\title{
CONDIÇÕES DE TRABALHO DOCENTE NOS PLANOS MUNICIPAIS DO PIEMONTE DA DIAMANTINA - BA
}

\author{
Osni Oliveira Noberto da Silva(*) \\ Theresinha Guimarães Miranda ${ }^{(* *)}$ \\ Miguel Angel Garcia Bordas ${ }^{(+*)}$
}

\section{INTRODUÇÃO}

A educação brasileira vem, desde os anos 60 do século XX, passando por alterações profundas. Muito por conta das exigências do modo de produção fordista, ocasionando também uma expansão sem planejamento do acesso à escola, já compreendida na época, como o caminho mais eficaz e seguro para a ascensão social (SANT’ANA, 2010). Entretanto essa circunstância acabou por gerar importantes modificações nas condições de trabalho dos docentes, como é explicado por Monlevade (2000):

O professor-operário, no meio de uma avassaladora inclusão de milhões de matrículas nos sistemas escolares primário e secundário, de 1950 a 1980, dobrou e até triplicou sua jornada, por pressão da demanda e/ou necessidade de sobrevivência. Este novo regime de trabalho impossibilitou, definitivamente, qualquer dedicação em preparar suas aulas e avaliar a produção dos alunos, cada vez mais numerosos (p. 63).

Assim, o que se percebeu foi a construção da figura de um professor entendido como um trabalhador que presta um serviço meramente técnico e burocrático, lhe impedindo de alcançar o principal objetivo da escola, que é a socialização do conhecimento e formação de indivíduos críticos, reflexivos e autônomos (CASTRO; BRITO, 2013).

Para tentar dirimir os problemas referentes a Educação brasileira, o governo federal produz, desde 1962, o Plano Nacional de Educação (PNE), que é um importante instrumento de planejamento e orientação das ações educacionais do Brasil para o futuro. $\mathrm{O}$ documento, a partir da

\footnotetext{
${ }^{(*)}$ Mestre e doutorando em Educação pela Universidade Federal da Bahia (UFBA). Professor do Depart amento de Ciências Humanas, Campus IV, da Universidade do Estado da Bahia (UNEB). Líder do Grupo de estudos, pesquisa e extensão em Educação Especial e Educação Física adaptada (GEPEFA) e integrante do Grupo de estudos sobre Educação Inclusiva e Necessidades Educacionais Especiais (GEINE).

${ }^{(* *)}$ Doutora em Educação pela Universidade de São Paulo (USP), com pós-doutorado pela Umeå University, Suécia. Professora do Programa de Pós-graduação em Educação da Universidade Federal da Bahia (UFBA). Integrante do Grupo de estudos sobre Educação Inclusiva e Necessidades Educacionais Especiais (GEINE).

${ }^{(* * *)}$ Doutor em Filosofia pela Universidad Complutense de Madrid, com pós -doutorado pela Universidad Autónoma de Barcelona, Espanha. Professor do Programa de Pós-graduação em Educação da Universidade Federal da Bahia (UFBA). Integrante do Grupo de estudos sobre Educação Inclusiva e Necessidades Educacionais Especiais (GEINE).
} 
Constituição de 1988 passou a ser estabelecido por lei, e desde a LDB de 1996 deve atuar em cooperação com estados e municípios, através de diretrizes e metas a serem alcançadas (BRASIL, 2014).

O PNE atual foi aprovado através da Lei federal 13.005, de 25 de junho de 2014, tendo atualmente a vigência obrigatória de 10 anos, neste caso, de 2014 a 2024. É composto de vinte metas e dez diretrizes a serem cumpridas através de estratégias específicas, sempre em articulação com os Planos estaduais e municipais. (BRASIL, 2014).

Desse modo, todo esse arcabouço legal, iniciado na esfera federal chega as localidades materializados nos Planos Municipais, que articulam as futuras ações dos municípios no período de 10 anos.

Assim, com a problemática apresentada e percebendo as urgências e emergências que este tema traz no que diz respeito ao trabalho docente, o artigo tem como objetivo descrever como as condições de trabalho dos professores são tratados nos planos municipais de educação das cidades da região do Piemonte da Diamantina.

A partir dessas reflexões, a investigação das condições de trabalho dos docentes se deu nos municípios que compõem a região do estado da Bahia conhecida como Piemonte da Diamantina, composta atualmente por nove municípios: Caém, Jacobina, Miguel Calmon, Mirangaba, Ourolândia, Saúde, Serrolândia, Umburanas e Várzea Nova (IBGE, 2012).

É importante destacar a justificativa deste artigo, que foi apresentar um novo olhar acerca da questão das condições de trabalho do professor na região do Piemonte da Diamantina e assim, poder contribuir com a produção de dados referenciais para estudos futuros sobre o tema, servindo como mais um elemento de auxilio na constituição de políticas públicas municipais para a educação, no sentido de colaborar com a melhora da educacional dos municípios, haja vista que existe poucos estudos sobre essa temática, especialmente sobre a região pesquisada.

\section{METODOLOGIA}

O estudo foi elaborado a partir da pesquisa documental, que segundo Gil (2010) favorece a utilização de fontes mais diversificadas e utiliza materiais que ainda não foram analisados, ou que podem ser reelaborados, dependendo dos objetivos propostos no estudo. Os materiais podem ser divididos entre documentos de primeira mão, que ainda não foram analisados, tais como: correspondências, diários, fotos, gravações de áudio e vídeo, documentos oficiais como leis e regimentos entre outros; e os documentos de segunda mão, que são materiais que já sofreram uma 
análise, que incluem: relatórios de arquivos públicos, arquivos particulares de instituições e domicílios, tabelas estatísticas etc.

As principais vantagens no uso dessa técnica de pesquisa são a durabilidade das fontes, pois documentos resistem por longo do tempo, se tornando fontes valiosas de dados de qualquer pesquisa, principalmente aquelas de cunho histórico; baixo custo da pesquisa, pois necessita do pesquisador apenas o tempo necessário para a análise dos documentos; e exige supre a necessidade de contato com os sujeitos da pesquisa, que por muitas circunstancias esse contato pode ser impossível (GIL, 2010).

Entretanto, as principais críticas à pesquisa documental dizem respeito à subjetividade dos documentos e a sua não-representatividade. Nesse caso, o autor, explica que:

É importante que o pesquisador considere as mais diversas implicações relativas aos documentos antes de formular uma conclusão definitiva. [...] algumas pesquisas elaboradas com base em documentos são importantes não porque respondem definitivamente a um problema, mas porque proporcionam melhor visão desse problema ou, então, hipóteses que conduzam a sua verificação por outros meios (GIL, 2010, p. 47).

Os documentos analisados foram os Planos Municipais de Educação dos nove municípios que compõem atualmente a região do Piemonte da Diamantina, Bahia: Caém, Jacobina, Miguel Calmon, Mirangaba, Ourolândia, Saúde, Serrolândia, Umburanas e Várzea Nova.

$\mathrm{Na}$ parte final da análise, o pesquisador precisar formar as conexões entre os dados colhidos com os "contextos, realidades culturais e históricas conectadas com a problemática analisada e constitutiva do objeto de pesquisa", pois "É neste momento que se inicia o esforço de organização e síntese, que vai ter seu momento final nas considerações conclusivas” (MACEDO, 2009, p. 100).

\section{ANÁLISE DOS PLANOS MUNICIPAIS DE EDUCAÇÃO}

A fim de auxiliar na construção dos PME, o governo federal lançou em 2014 um caderno de orientações direcionados aos grupos de trabalho dos diversos municípios, se constituindo como um manual, onde é apresentado todas as etapas de construção, desde o diagnóstico, o debate com a comunidade, a catalogação dos indicadores, a construção das metas e das estratégias para alcançalas, a redação do projeto de lei, a tramitação e sua aprovação, como pode ser resumido no trecho abaixo:

[...] é fundamental considerar que o PME deve ser do município, e não apenas da rede ou do sistema municipal. O Plano Municipal de Educação é de todos que moram no 
município; portanto, todas as necessidades educacionais do cidadão devem estar presentes no Plano, o que vai muito além das possibilidades de oferta educacional direta da Prefeitura. Também não se trata do plano de uma administração da Prefeitura ou da Secretaria Municipal de Educação, pois atravessa mandatos de vários prefeitos e dirigentes municipais de educação. $O$ trabalho pressupõe o envolvimento das três esferas de gestão (federal, estadual e municipal) e de representações dos diversos segmentos da sociedade, mas não deixa de conferir peso e importância ao papel dos dirigentes municipais.

[...] O PME deve se articular aos demais instrumentos de planejamento. Os insumos necessários para a execução dos planos de educação terão de constar nos orçamentos da União e dos estados para que apoiem técnica e financeiramente os municípios ao longo da década. Na Prefeitura, instrumentos de planejamento terão de se vincular ao plano decenal de educação: Plano Plurianual (PPA), Lei de Diretrizes Orçamentárias (LDO), Lei Orçamentária Anual (LOA), Plano de Ações Articuladas (PAR), entre outros.

[...] Por fim, uma premissa indispensável de trabalho é o fato de que o PME tem de ter legitimidade para ter sucesso. Planos construídos em gabinetes ou por consultores alheios à realidade municipal tendem ao fracasso, mas um PME submetido ao amplo debate incorpora a riqueza das diferentes visões e vivências que a sociedade tem sobre a realidade que deseja alterar. Somente um Plano Municipal de Educação legítimo pode contar com o apoio de todos para monitorar seus resultados e impulsionar a sua concretização, através da mobilização da sociedade ao longo dos seus dez anos de vigência (BRASIL, 2014, p. 07).

Apesar de não existir claramente no documento nenhuma imposição rigorosa, o Caderno de orientações garantiu certa uniformidade na forma e no conteúdo dos planos municipais, ainda que de regiões diferentes, preservando a esperada sintonia com os Planos Nacional e Estadual. Além disso o caderno orienta que "os dados e informações mais relevantes em mãos, deve-se comparar a realidade do município para esta meta com as metas assumidas nos Planos Estadual e Nacional de Educação" (BRASIL, 2014, p. 16).

Havia um prazo dado aos estados e municípios para a publicação de seus Planos educacionais, alguns estados e muitos municípios não conseguiram cumpri-lo, como afirmam Nascimento et al. (2017):

O artigo oitavo da Lei 13.005/2014 determina que todos os estados, o distrito federal e todos os municípios deveriam elaborar ou adequar seus Planos de Educação até a data 
de 24 de julho de 2015. Mesmo contando com a assistência técnica do MEC/SASE/ CONSED e UNDIME, em 25 de julho de 2016 ainda tínhamos 03 estados e 49 municípios sem planos de educação (p. 125-126).

Segundo Silva e Oliveira (2016) o atraso na publicação dos Planos municipais de Educação gerou algumas consequências, sendo que a mais direta tratou de penalizar os municípios, inviabilizando o recebimento de recursos vindos diretamente do Governo Federal. E os autores ainda complementam:

Contudo, na ausência dos pressupostos necessários ao exercício desta autonomia, os documentos oficiais do Ministério da Educação passam a exercer forte influência no delineamento dos PME. Ao exigir, sob a óptica da cooperação entre os entes federados, o alinhamento dos planos municipais aos planos nacionais e, sincronicamente, estabelecer mecanismos de responsabilização, desconsiderando o que, de fato, coloca-se como competência dos municípios, o MEC abriu precedentes para que muitos gestores locais incluíssem nas metas dos PME estratégias que, na conjuntura legal existente no país, seriam de competência dos Estados e do Governo Federal, transformando estes precedentes em marcos legais municipais. (SILVA; OLIVEIRA, 2016, p. 118).

Dos Planos Municipais de Educação (PME) das nove cidades, um foi publicado em 2011, um em 2014, outro em 2017 e seis foram aprovados em 2015, como mostrado na tabela 1. Por se tratar de planos decenais (período de 10 anos), nenhum deles teve sua vigência encerrada antes da finalização de nossa pesquisa, o que se apresenta como um elemento limitador que impede de tirarmos conclusões acerca do cumprimento das metas, com exceção daquelas que explicitam um prazo já encerrado. nove dos PME pesquisados foram publicados antes do Plano Estadual. Somente o PME de Umburanas foi constituído antes da vigência do PNE atual. Apenas o plano de Miguel Calmon foi publicado depois do PNE e PEE e juntamente com Jacobina foram os 2 únicos a serem publicados depois do prazo dado pela Lei 13.005/2014. 
Tabela 1. Planos municipais de Educação das cidades investigadas

\begin{tabular}{|c|c|c|}
\hline Município & Lei municipal & Vigência \\
\hline Caém & Lei no 455 de 22/05/2014 & 2014 a 2024 \\
\hline Jacobina & Lei $\mathrm{n}^{\circ} 1333$ de 19/09/2015 & 2015 a 2025 \\
\hline Miguel Calmon & Lei no 586 de $18 / 12 / 2017$ & 2017 a 2027 \\
\hline Mirangaba & Lei no 238 de 22/06/2015 & 2015 a 2025 \\
\hline Ourolândia & Lei $n^{\circ} 327$ de $23 / 07 / 2015$ & 2015 a 2025 \\
\hline Saúde & Lei $n^{\circ} 376$ de $25 / 06 / 2015$ & 2015 a 2025 \\
\hline Serrolândia & Lei $n^{\circ} 568$ de $25 / 06 / 2015$ & 2015 a 2025 \\
\hline Umburanas & Lei $n^{\circ} 146$ de 21/12/2011 & 2011 a 2021 \\
\hline Várzea Nova & Lei no 486 de 19/06/2015 & 2015 a 2025 \\
\hline
\end{tabular}

Fonte: Autoria própria.

Todos eles foram encontrados na internet, no site "PNE em movimento", do governo federal que mantem um banco de dados com o conjunto de Planos Municipais de Educação das cidades do Brasil, através do endereço eletrônico: <http://pne.mec.gov.br/planos-de-educacao/situacao-dosplanos-de-educacao>.

Esta analise procurou estabelecer um perfil que nos permite delinear um padrão dos mesmos, a partir de características comuns, visando entender como as condições de trabalho dos professores estão sendo apontados nos Planos municipais de Educação existentes no Piemonte da Diamantina.

Foi possível observar em todos os PME que apesar de algumas diferenças próprias, muitos elementos comuns foram encontrados nos Planos Municipais, como será apresentado a seguir.

Sobre as condições de trabalho docente, todos os planos possuem pelo menos 1 meta sobre esse tema, muitos com o nome de "valorização do trabalho docente". O foco maior foi em relação a salário, tratado por todos. Em 3 planos (JACOBINA, 2015; MIGUEL CALMON, 2017; VARZEA NOVA, 2015) tem como meta igualar o salário levando em conta o piso nacional do magistério. Também foi observado a preocupação em atualizar e/ou reformular o Plano de carreira docente, em todos os planos municipais de educação analisados, principalmente para que haja a atualização com o piso nacional de educação. Ainda que a conquista de um piso nacional salarial docente deva ser comemorada, o que se observa é que o "piso", em muitos casos é tratado como "teto", sem um maior dialogo acerca dos vencimentos docentes, onde fica a impressão de que só há essa equiparação financeira apenas por imposição da Lei.

Em quatro planos municipais (CAÉM, 2015; OUROLÂNDIA, 2015; UMBURANAS, 2011; VÁRZEA NOVA, 2015) é apresentado a busca na equiparação salarial dos professores, aos profissionais de mesmo nível acadêmico. A meta parecer ser muito difícil de ser concretizada, 
muito por conta dos ranços históricos que ocorrem principalmente nos municípios, em relação a discrepância entre os salários dos professores com os outros profissionais de ensino superior (principalmente quando comparado aos vencimentos que os municípios oferecem aos médicos).

Entretanto, como essa meta também está inserida no Plano Nacional de Educação, a concretização desta só poderá ser considerada a nível nacional, se for implantada uma série de incentivos a nível federal, como já é feita, através do FUNDEB ${ }^{1}$, por exemplo.

Em todos os PME existe a preocupação, enquanto meta a ser alcançada, em capacitar os professores já pertencentes ao quadro do município para o nível superior, como pode ser observado por exemplo no trecho do Plano de Jacobina:

Implementar cursos e programas especiais para assegurar formação específica na educação superior, nas respectivas áreas de atuação, aos docentes com formação de nível médio na modalidade normal, não licenciados ou licenciados em área diversa da de atuação docente, em efetivo exercício. (JACOBINA, 2015, p. 159).

Em seis planos (JACOBINA, 2015; MIGUEL CALMON, 2017; OUROLÂNDIA, 2015; SAÚDE, 2015; UMBURANAS, 2011; VÁRZEA NOVA, 2015) existe a exigência da contratação de docentes apenas mediante concurso. Essa medida já é prevista no artigo 67, da Lei de Diretrizes e Bases em 1996, já citada nessa tese. Se ainda é uma preocupação dos municípios, significa que não é cumprido em usa totalidade.

Cinco PME (CAÉM, 2015; MIGUEL CALMON, 2017; OUROLÂNDIA, 2015; UMBURANAS, 2011; VÁRZEA NOVA, 2015) trazem a obrigação de só garantir a contratação de professores que possuem nível superior. O caso mais curioso é o de Umburanas onde na meta 9 do item 7 intitulado "Valorização dos profissionais da educação" de seu PME, diz que "a partir de 2015 o município só admitirá professores graduados" (UMBURANAS, 2015, p. 109). Curiosamente a meta 10 informa que "a partir de 2015 o município só admitirá professores com formação mínima para exercício do magistério (com base do art. $62^{2}$ da LDB e PNE)." (UMBURANAS, 2015, p. 109).

\footnotetext{
${ }^{1}$ O FUNDEB, Fundo de Manutenção e Desenvolvimento da Educação Básica e de Valorização dos Profissionais da Educação, é um fundo especial para a educação, formado por recursos federais e em maior parte estaduais e municipais, sendo a totalidade de seu recurso direcionada para a educação básica.

${ }^{2}$ O artigo 62 da LDB, em sua redação mais atualizada pela Lei 13.415, de 2017, afirma que "A formação de docentes para atuar na educação básica far-se-á em nível superior, em curso de licenciatura plena, admitida, como formação mínima para o exercício do magistério na educação infantil e nos cinco primeiros anos do ensino fundamental, a oferecida em nível médio, na modalidade normal" (BRASIL, 2017).
} 
Por ter sido publicado em 2011 o plano de Umburanas vigente já está em desconformidade com o atual Plano Nacional de Educação, principalmente no que se refere a meta 15 do PNE que procura "garantir, em regime de colaboração entre a União, os estados, o Distrito Federal e os municípios, no prazo de um ano de vigência deste PNE [...] que todos os professores e as professoras da educação básica possuam formação específica de nível superior, obtida em curso de licenciatura na área de conhecimento em que atuam (BRASIL, 2014, p. 78).

Esse contrassenso abriu margem para que a meta 9 do PME de Umburanas fosse desconsiderada, como pode ser observado analisando o último concurso realizado no referido município, através de Edital 01/2016, onde foram oferecidas 60 vagas para o cargo de "Professor de Educação Básica", 20 horas e pré-requisito e escolaridade mínima "Nível Médio Completo com Formação em Magistério (UMBURANAS, 2016).

Mororó e Couto, ao pesquisar sobre as condições dos professores na Bahia, através da PARFOR, perceberam que a situação acima retratada ainda é uma prática muito comum em diversos municípios do estado:

[...] é possível perceber o quanto os formuladores das políticas públicas para a formação de professores no estado da Bahia e os gestores estaduais e municipais têm ignorado o critério da formação em nível superior em cursos de licenciatura plena para o exercício da docência no estado. $\mathrm{E}$ isso pode ser averiguado através de outros indicadores como, por exemplo, o fato de muitas prefeituras continuarem preterindo a formação em Pedagogia em relação à formação em nível médio na modalidade normal para a admissão de novos docentes concursados, convivendo, assim, no interior das gestões municipais e estaduais, ao mesmo tempo, com ações de formação de seus docentes em nível superior e a admissão de novos sem essa formação, agora considerada adequada. Futuramente, isso pode vir a estabelecer um "círculo vicioso" sem data para terminar em relação à formação inicial em serviço, pois os docentes das redes públicas, sem formação em nível superior, estarão sempre precisando da formação nesse nível. Em razão do pouco investimento financeiro dos municípios com os programas emergenciais de formação de seus docentes, provavelmente seja menos dispendioso para as prefeituras continuarem com docentes em desvio de função do que contratar (ou selecionar) docentes já graduados que iniciarão a carreira quase que no topo do plano salarial (MORORÓ; COUTO, 2015, p. 32).

A formação continuada (levando em conta tanto cursos de especializações quanto de mestrado e doutorado) aparece como outro importante item, sendo citado em 8 planos municipais 
(CAÉM, 2014; JACOBINA, 2015; MIGUEL CALMON, 2017; MIRANGABA, 2015; OUROLÂNDIA, 2015; SERROLÂNDIA, 2015; UMBURANAS, 2011; VÁRZEA NOVA, 2015).

Entretanto, alguns autores como Silva e Oliveira (2016) levantam a questão da obrigatoriedade dos municípios em cumprir metas referentes à formação continuada (inclusive em relação a elevação nas taxas de matricula e formatura de professores com mestrado e doutorado), haja vista que é incomum que municípios brasileiros tenham instituições de ensino superior, ainda mais levando em consideração que a competência da formação em nível superior constitucionalmente é de competência do governo federal.

Esse problema não é exclusividade dos municípios da região do Piemonte da Diamantina. Um estudo de Silva e Oliveira (2016) sobre a análise dos PME de quatorze municípios da região noroeste do estado de São Paulo. Nele, foi observado que em onze planos municipais "que perspectivam a ampliação de matrículas na educação superior e do número de mestres e doutores nas instituições de ensino superior são encontradas nos planos seguidas de estratégias idênticas às elencadas no plano nacional" (SILVA; OLIVEIRA, 2016, p. 117). Entretanto, os autores alertam que:

[...] a inexistência de instituições de ensino superior em grande parte dos municípios brasileiros não os isenta de traçar algumas medidas para colaborar com estas metas, no entanto, responsabilizar-se pelo seu cumprimento seria arriscado em um contexto de recursos, muitas vezes, insuficientes (p. 120).

Foi possível observar que todos os Planos Municipais de Educação analisados nessa tese citam a Universidade do Estado da Bahia, principalmente do seu campus IV, única Instituição de Ensino Superior pública do Piemonte da Diamantina, como uma peça importante para a formação inicial e continuada dos professores, seja pela oferta dos cursos regulares de graduação e pósgraduação ou através do programa de formação docente conhecido pela sigla PARFOR $^{3}$.

Contudo, em sete deles (JACOBINA, 2015; MIGUEL CALMON, 2017; MIRANGABA, 2015; OUROLÂNDIA, 2015; SERROLÂNDIA, 2015; UMBURANAS, 2011; VÁRZEA NOVA, 2015) aparecem também a importância das instituições particulares de ensino, tanto presenciais quanto a distância. O plano de Umburanas fala da existência de uma parceria entre o município e uma faculdade privada, onde a prefeitura cede o espaço físico de uma escola para a instalação da

\footnotetext{
${ }^{3}$ Plano Nacional de Formação de Professores da Educação Básica (PARFOR) é um Programa do governo federal que objetiva suprir a carência emergencial de professores com Licenciatura no Brasil e foi implantado em regime de colaboração entre a Coordenação de Aperfeiçoamento de Pessoal de Nível Superior (CAPES), os estados, municípios e as Universidades públicas.
} 
instituição mas não deixa claro qual a contrapartida recebida, com exceção da própria chegada dela na cidade.

Também observamos que apenas os planos de Saúde e Miguel Calmon trazem como estratégica a liberação da jornada de trabalho dos professores para o aperfeiçoamento docente. No caso de Saúde a liberação está condicionada a:

$20 \%$ da jornada de trabalho para os profissionais da Educação matriculados em programas de mestrado e doutorado, bem como a liberação para a participação em eventos científicos em áreas afins (quando da apresentação de trabalhos), sem prejuízo dos vencimentos (SAÚDE, 2015, p. 64).

Jacobina e Miguel Calmon, além do afastamento docente para estudos, também mencionam a possibilidade de incentivo financeiro (tipo bolsa) para ajudar a custear a formação continuada do professor, como pode ser observado a seguir na transcrição da estratégia 2 da meta 16 do PME de Miguel Calmon: "Incentivar os profissionais da educação a realizarem cursos de pós-graduação através de incentivo financeiro, em seus vencimentos mensais para custear despesas inerentes ao curso, bem como ajuda para deslocamento.” (MIGUEL CALMON, 2017, p. 94).

O fato de que em apenas 3 Planos municipais foram observadas preocupações e proposições de metas que contemplem a qualificação, no que tange as condições docentes para o desenvolvimento de estudos, é uma manifestação de que esse tema ainda não é levado a sério na maioria das gestões municipais, onde prevalece a ideia de que importa apenas o tempo gasto como aluno em sala de aula, sem contar o período de estudos. Isso acaba por exigir grandes sacrifícios dos docentes que buscam a qualificação profissional. Esta análise é corroborada por Mororó e Couto (2015) que ainda complementam:

Tendo que "dar conta" de suas atividades de formação e de sua rotina de trabalho, os professores-discentes do PARFOR nem bem estudam, nem bem ensinam, comprometendo, assim, os tão desejados índices de qualidade vislumbrados para a educação brasileira. Tratar como "heróis" esses homens e mulheres, a nosso ver, redime os gestores públicos da má condução das políticas públicas de formação e desresponsabiliza as IPES $^{4}$ de exigir e de promover as condições dignas para que essa formação de fato se efetive. (MORORÓ; COUTO, 2015, p. 36).

Apenas nos planos municipais dos municípios de Mirangaba e Saúde foi possível observar a menção a preocupação com a saúde dos professores municipais. No primeiro, ao tratar sobre a criação, "até o final da vigência deste PME, o Plano de Saúde do Servidor Público Municipal"

\footnotetext{
${ }^{4}$ Instituições públicas de ensino superior.
} 
(MIRANGABA, 2015, p. 61). No segundo, ao falar sobre a criação de "Convênios com Instituições de Ensino Superior e na área de saúde, para programas de qualidade de vida para o profissional da educação como: vacinação, prevenção aos problemas de saúde ocupacional” (SAÚDE, 2015, p. 65).

É temeroso que somente duas PME tragam preocupações com a saúde dos docentes, haja vista que diversos estudos, nacionais e internacionais (UNESCO, 2005; CHAVES, 2009; SILVA; GRANDI, 2015; SANTOS; WANZINACK, 2017), concordam que a profissão docente gera um alto índice de adoecimento, muito por conta de elementos que influenciam nas condições de trabalho, tais como o número elevado de alunos, problemas de barulho e acústica das salas, violência, stress e outros problemas de ordem psicológica.

Ademais, é importante enfatizar que todos esses elementos contidos nos Planos são intimamente dependentes do financiamento, com a captação de recursos em suas diversas esferas, fortemente influenciados pelas questões políticas, tanto nacionais quanto locais e implicam diretamente na efetividade dos Planos Municipais e consequentemente nas condições de trabalho docente. Assim, pensar na problemática do financiamento é essencial para que ocorram alterações significativas na educação do país, como é ratificado por Vicente et al. (2015):

Há urgência em avançar o debate acerca do financiamento da educação para trazer um novo conceito social, e de melhorias para a educação no Brasil, uma ideia de desenvolvimento no princípio de igualdade. Um sistema econômico que beneficia a grande maioria da população. Há necessidade de se investir mais em educação, pois na atualidade verificamos a ausência de recursos para a formação escolar de qualidade dos brasileiros (p. 224).

Porém, houve um agravamento do quadro, em decorrência das alterações nos repasses dos recursos financeiros, principalmente depois da aprovação da Emenda Constitucional 95/2016 ${ }^{5}$ dos gastos públicos que afeta diretamente a concretização da maioria das Metas dos Planos Municipais de Educação, situação alertada por Nascimento et al. (2017):

Outro aspecto essencial a ser pensado é a questão do financiamento da educação e da dependência do município em relação à União, para a condução das políticas educacionais. No modelo atual, o sistema municipal de educação (e os municípios), sofrem as consequências de uma repartição de responsabilidades, cuja conta não se alinha com os investimentos públicos transferidos aos municípios e até mesmo com a sua capacidade arrecadatória. Neste sentido, o município não costuma pensar políticas

\footnotetext{
${ }^{5}$ A Emenda Constitucional 95 foi aprovada em 2016 e visa basicamente restringir os gastos públicos nos 20 exercícios financeiros seguintes.
} 
de longo prazo para a educação, detendo-se em decisões parciais e momentâneas, dentro de um contexto político-administrativo, ora favorável, ora desfavorável (p. 124).

Desse modo, com a atual conjuntura financeira de corte de gastos do governo federal, parece ser muito difícil que as metas, tanto dos Planos nacional e estaduais quanto os Planos municipais de Educação, consigam ser concretizadas em sua plenitude. Na verdade, trazendo um cenário mais pessimista, se não houver nos próximos anos uma suplementação financeira para o cumprimento das metas, elas poderão ser completamente inviabilizadas.

\section{CONSIDERAÇÕES FINAIS}

Em suma, os planos apresentam uma baixa cooperação intermunicipal, ainda que desfrutem problemas similares. Entretanto expõem o que se esperam deles, no que tange ao diagnóstico de suas realidades e autonomia relativa no que diz respeito a criação de metas e estratégias para melhorar a educação de seus respectivos municípios.

Entretanto é perceptível que os textos apresentam diferenças significativas entre si, quando tratam do mesmo objeto. Outro aspecto percebido foi a dificuldade em discutir temas que muitas vezes fogem da alçada dos municípios, mas que constam no Plano Nacional, caso da educação de nível superior. Sobre essas dificuldades, Nascimento (2007) afirma que vem de longa data e são agravados pela própria dinâmica da hierarquia sui generis da organização federativa brasileira:

As condições dos docentes para estudo, como diminuição de carga horária e incentivo financeiro; e a preocupação com a saúde desses trabalhadores, são dois temas extremamente importantes, mas que infelizmente foram encontrados em apenas um terço dos Planos analisados.

Assim, compreendendo a importância das diversas forças políticas em que esses documentos foram criados, muitas vezes na base do consenso possível, urge a necessidade da contínua fiscalização por parte da população, para que as metas explicitadas no Plano Nacional e Plano Estadual, referentes as condições de trabalho docente, sejam de fato cumpridas. 


\section{REFERÊNCIAS}

BRASIL. Ministério de Estado da Educação e do Desporto. Portaria Ministerial $\mathrm{n}^{\circ} 1793$ SEESP/MEC, de 27 de dezembro de 1994. Diário Oficial da União. Brasília: 28 dez. 1994.

Lei 13.005, de 25 de junho de 2014. Aprova o Plano Nacional de Educação (PNE) e dá outras providências. Diário Oficial da União. Brasília: 25 jun. 2014.

Lei 13.146, de 6 de julho de 2015. Institui a Lei Brasileira de Inclusão da Pessoa com Deficiência. Diário Oficial da União. Brasília: 6 jul. 2015.

CAÉM. Lei 455 de 22 de maio de 2014. Institui o Plano Municipal de Educação e dá outras providências. Diário Oficial da União. Brasília: 22 maio 2014.

CASTRO, Alda Maria Duarte Araujo; BRITO, Fabiana Erica de. As condições de trabalho em tempos de reestruturação produtiva: foco na educação básica do RN. In: NETO, Antonio C.; OLIVEIRA, Dalila A.; VIEIRA, Livia F. (Orgs.). Trabalho Docente: desafios no cotidiano da educação básica. Campinas: Mercado de Letras; Natal, 2013.

CHÁ VEZ, Rodrigo Cornejo. Condiciones de trabajo y bienestar/malestar docente en profesores de enseñanza media de Santiago de Chile. Educ. Soc., Campinas, vol. 30, n. 107, p. 409-426, maio/ago. 2009.

GIL, Antonio Carlos. Como elaborar projetos de pesquisa. 5. ed. São Paulo: Atlas, 2010.

INSTITUTO BRASILEIRO DE GEOGRAFIA E ESTATÍSTICA/IBGE. Cidades. [S.l.:s.n, s/d]. Disponível em: <http://www.cidades.ibge .gov.br/v3/cidades/home-cidades>. Acesso em: 15 dez. 2016.

JACOBINA. Lei 1.333, de 19/09/2015. Plano Municipal de Educação Jacobina. Bahia: 2015-2025.

MACEDO, Roberto Sidnei. Outras luzes: um rigor intercrítico para uma etnopesquisa política. In: MACEDO, Roberto Sidnei; GALEFFI, Dante; PIMENTEL, Álamo. Um rigor outro: sobre a questão da qualidade na pesquisa qualitativa. Salvador: Edufba, 2009.

MIGUEL CALMON. Lei 586, de 18/12/17. Aprova o Plano Municipal de Educação - PME. Miguel Calmon, BA, 2017.

MIRANGABA. Lei 238, de 22/06/2015. Plano Municipal de Educação - PME. Mirangaba, BA, em conso2017.

MONLEVADE, João Antônio C. Valorização salarial dos professores: o papel do piso salarial profissional nacional como instrumento de valorização dos professores da educação pública básica. 2000, 307 p. Tese (Doutorado em Educação), Universidade Estadual de Campinas, Campinas, 2000.

MORORÓ, Leila Pio; COUTO, Maria Elizabete Souza. As condições de formação do professor-discente do PARFOR na Bahia. Horizontes, v. 33, n. 1, p. 29-38, jan./jun. 2015

NASCIMENTO, Gilvânia da Conceição; GROSSI JUNIOR, Geraldo; PEREIRA, Jhonata Moreira. Planos municipais de educação - perfil dos municípios que não possuíam plano municipal de educação no segundo ano de vigência da Lei 13.005/14. Revista Exitus. Santarém/PA, v. 1. 7, n. 1, p. 108-130, jan./abr. 2017.

OUROLÂNDIA. Lei 327, de 23 /07/2015. Plano Municipal decenal de Educação, para o decênio $2015-2025$. Ourolandia, BA, 2018.

SANT’ANA, Raquel Santos. (Orgs.); LOURENÇO, Edvânia; NAVARRO, Vera, BERTANI, Iris; SILVA, José F.S. O Avesso do Trabalho II. São Paulo: Expressão Popular, 2010.

SANTOS, Josi Kelly Leite; WANZINACK, Clóvis. Saúde docente: um estudo de caso nas escolas municipais de ensino fundamental do município de matinhos - Paraná. Revista Electrónica de Investigación y Docencia (REID), 17, p. 115-128, enero, 2017.

SAÚDE. Lei 376, de 25/06/2015. Plano Municipal de Educação - PME. Saúde BA, 215.

SERROLÂNDIA. Lei 568, de 25/06/2015. Plano Municipal de Educação - PME. Serrolândia, BA, 2015.

SILVA, Laíse Karine; GRANDI, Ana Lúcia. Adoecimento mental em docentes do ensino fundamental I e II. In: Anais da V Jornada de Iniciação Científica da UENP. Universidade Estadual do Norte do Paraná. Bandeirantes, 2015.

SILVA, Leandro Vitoriano; OLIVEIRA, Maria Eliza Nogueira. O Plano Municipal de Educação: da autonomia construída à autonomia decretada. Revista Teias, v. 17, n. 47, p. 107-123, out.-dez. 2016. 
UMBURANAS. Lei 146 ,de 21/12/2011. Plano Municipal de Educação de Umburanas: traçando diretrizes, objetivos e metas para a melhoria na qualidade da educação Umburanense. Umburanas, BA, 2011. Umburanas.

Edital 001/2016. Concurso público para provimento de vagas no quadro efetivo da Prefeitura Municipal de

UNESCO. Condiciones de trabajo y salud docente: estudios de casos en Argentina, Chile, Ecuador, México, Perú y Uruguay. Santiago de Chile: UNESCO-OREA LC, 2005.

VÁRZEA NOVA. Lei 486, de 19/06/2015. Plano Municipal de Educação C PME. em consonância com a Lei 13.005/2014, que trata do Plano Nacional de Educação - PNE.

VICENTE, Vinicius Renan R; RAMOS, Carlos Vinícius; MOREIRA, Jani Alves Silva. O financiamento da Educação Básica no Brasil: em discussão a vinculação de recursos. Revista Temparzea, Noba, BA, 2015. 


\title{
RESUMO
}

Este artigo tem como objetivo investigar como as condições de trabalho dos professores, são tratados nos planos municipais de educação das cidades da região do Piemonte da Diamantina. $O$ estudo foi desenvolvimento a partir da pesquisa documental e análise dos dados foi feita através da Hermenêutica objetiva. É possível observar nos planos que existe uma baixa cooperação intermunicipal, ainda que eles desfrutem de problemas similares. Outro aspecto percebido foi a dificuldade em discutir temas que muitas vezes fogem da alçada dos municípios, mas que constam no Plano Nacional, caso da educação de nível superior. As condições dos docentes para estudo, como diminuição de carga horária e incentivo finance iro; e a preocupação com a saúde desses trabalhadores, são dois temas extremamente importantes, mas que infelizmente foram encontrados em apenas um terço dos Planos analisados. Entretanto os planos expõem o que se esperam deles, no que tange ao diagnóstico de suas realidades e autonomia relativa no que diz respeito a criação de metas e estratégias para melhorar a educação de seus respectivos municípios.

Palavras-chave: Condições de trabalho docente. Plano Municipal de Educação. Políticas educacionais.

\section{CONDITIONS OF TEACHING WORK IN THE MUNICIPAL PLANS OF THE PIAMONTE DIAMANTINA - BAHIA}

\begin{abstract}
This paper aims to investigate how teachers' working conditions are treated in the municipal education plans of the cities of the Piedmont region of Diamantina. The study was development from documentary research and data analysis was done through objective Hermeneutics. It is possible to observe in the plans that there is a low inter-municipal cooperation, although they enjoy similar problems. Another perceived aspect was the difficulty in discussing subjects that often escape the jurisdiction of the municipalities, but which are included in the National Plan, in the case of higher education. The conditions of teachers for study, such as reduction of workload and financial incentive; and concern for the health of these workers, are two extremely important issues, but unfortunately they were found in only one third of the Plans analyzed. However, the plans explain what is expected of them, regarding the diagnosis of their realities and relative autonomy regarding the creation of goals and strategies to improve the education of their respective municipalities.
\end{abstract}

Keywords: Teaching work conditions. Municipal Plan of Education. Educational policies.

\section{CONDICIONES DEL TRABAJO DOCENTE EN LOS PLANES MUNICIPALES DE LA DIAMANTINA PIAMONTE - BAHIA}

\section{RESUMEN}

Este documento tiene como objetivo investigar cómo se tratan las condiciones de trabajo de los docentes en los planes de educación municipal de las ciudades de la región de Piamonte de Diamantina. El estudio se desarrolló a partir de investigaciones documentales y el análisis de los datos se realizó a través de la hermenéutica objetiva. Es posible observar en los planes que existe una baja cooperación intermunicipal, aunque tengan problemas similares. Otro aspecto percibido fue la dificultad para discutir temas que a menudo escapan a la jurisdicción de los municipios, pero que están incluidos en el Plan Nacional, en el caso de la educación superior. Las condiciones de los profesores para el estudio, tales como la reducción de la carga de trabajo y el incentivo financiero; Y la preocupación por la salud de estos trabajadores, son dos temas extremadamente importantes, pero desafortunadamente se encontraron en solo un tercio de los Planes analizados. Sin embargo, los planes explican lo que se espera de ellos, con respecto al diagnóstico de sus realidades y relativa autonomía en cuanto a la creación de objetivos y estrategias para mejorar la educación de sus respectivos municipios.

Palabras clave: condiciones de trabajo docente. Plan Municipal de Educación. Políticas educativas. 